\section{MATHEMATICS AT THE NATIONAL PHYSICAL LABORATORY}

$\mathrm{T}^{\mathrm{H}}$ HE National Physical Laboratory is proposing to extend its activities by the establishment of a Mathematics Division. It may be of interest to sketch the scope of the project as it is at present planned, though the plans may, of course, be modified in the light of growing experience.

The general aim may best be described by an extract from the report of an Interdepartmental Technical Committee recently appointed to consider the advisability of setting up such an establishment. This Committee decided that there is a strong case for an organization which would: (1) undertake research into new computing methods and machines ; (2) encourage the development of new computing methods and instruments and the dissemination of knowledge of them and of existing methods ; (3) deal with problems arising from statistical science, in particular by assisting in the application of statistical methods to research, development and production problems in industry and to problems arising in the physical sciences and engineering, and by research into new statistical techniques; it would in general exclude economic, sociological and biological statistics from its purview; (4) advise on the need for new mathematical tables, and, if necessary, prepare them ; (5) provide computing services for Government departments and industry; (6) act as consultant on mathematical matters to Government departments and industry.

The Committee recommended that the National Physical Laboratory should undertake these duties, and with the view of doing so the Mathematics Division is being established. It is proposed at first to organize it in thre日 sections, concerned respectively with computations using existing machines; with statistics; and with work of the differential analyser type, including the construction of new types of machines.

For the computing section there will be a full range of modern calculating machines, including the punched-card type, and very likely new machines may be developed for specialized purposes. There will be a comprehensive library of mathematical tables. Any spare time of the section will be devoted to the tabulation of functions of general utility.

The second section will be concerned with statistical methods and their use in industry. The methods of 'quality control' of production are now well established in industry, and at the practical levels can look after themselves, but there is room for much work in a general oversight of the subject, and in the further study of data provided by 'Q.C.' records. There is also much scope for the use of statistical methods in the planning of experiments in physics and engineering in the same way as is already well established through the work of Fisher and others in the biological sciences. It is not contemplated that the work of the section should extend into biology or sociology, as this would enlarge its scope out of all proportion, and would bring it into fields which are inappropriate for the National Physical Laboratory.

The third section will deal with work using what may be described as analytical engines, including the differential analyser and other machines both existing and awaiting invention. From progress already made elsewhere in such matters, it is certain that this field is capable of great developments, but it is more difficult to predict in what directions they will lie.

In setting up a Mathematics Division there is no intention of supplanting other existing activities. There are already in the Government service a number of mathematical groups fulfilling important specialized functions; for example, the Nautical Almanac Office. These will continue to work as before, but the new Division should be able to provide service for them by advising on their methods. and perhaps assisting them in times of pressure. So too there will be no supersession of industrial work in mathematics, but it is intended that there shall be close co-operation. This should encourage the development inside industry of the use of mathematical methods, which recent experience has undoubtedly shown to be of the greatest value.

\section{BRITISH LIBRARY OF POLITICAL AND ECONOMIC SCIENCE}

$7 \mathrm{HE}$ annual report of the British Library of Political and Economic Science, which is housed in the London School of Economics and Political Science, for the year ended July 31,1944 , includes a retrospect of 1933-44. In this ten years the Library added 104,450 bound volumes to its shelves, and 154,368 cards to its author catalogue. During 1934-35 the Library added to its shelves 4,549 treatises and was receiving currently 3,339 periodical titles, as against 5,445 treatises and 4,506 periodicals in 1938-39, the last year of normal working. In the years immediately preceding the War, much was done to strengthen the staff and to improve its status. This larger and more highly qualified staff enabled the whole of the administration of the Library to be reorganized and the services to be greatly improved.

The survey is largely one of the work of 1934-39. Intensive efforts were made with much success to set up an international library truly representative of the social sciences. Many complete sets of import. ant periodicals were secured, and gaps filled in existing sets. A new system of combined work-card and draft-catalogue-card was devised to eliminate wasteful routine tasks, and, in conjunction with a new arrangement of accession registers, was used to enable the Library to check its intake by country and by subject. A revision of the existing catalogue was undertaken, and after nine and a half years intensive work has at last been completed. With regard to cataloguing the uncatalogued material, all the non-official periodicals and almost all the official periodicals held by the Library have been included; 12,732 old pamphlets have also been catalogued, although many times that number still await attention, and 5,482 non-serial official publications have been catalogued and entered in chronological sequence under the issuing department of the relevant Government. In addition, 4,852 cards have been entered for treatises discovered to be in the Library but not in the cata. logue. The separate catalogue to the Edward Fry Library of International Law has been revised and some 5,000 duplicate entries inserted in the main catalogue.

One of the many real needs of the Library is an adequate catalogue room to hold not only the rapidly expanding catalogues, but also adjacent thereto a much larger collection of bibliographies and works of reference. The principal stacking problem has been that of space. Reviewing the improvements made in 
the housing of readers and the staff of the Library, the survey points out that these improvements led to a heavy increase in the use of the Library. At the conclusion of the War the number of readers wishing to consult the Library's international collections in history, politics, government, economics, law and international law will undoubtedly present the Library Committee with an anxious and difficult task. A little is being done to improve the lending library established for undergraduate students. The seminar collections, like the present lending library, are too small, and those systems should be developed into real ancillary libraries. The physical damage suffered by the Library and its collection through enemy action has so far been negligible, and despite many changes in the Library staff, which has now only six members who are fully conversant with its activities, work is being carried on in the same spirit as in 1940-41.

According to the annual report for the year ended July $31,1944,1,675$ works, 1,000 pamphlets, 206 non-serial official reports, excluding British Parliamentary Papers and Public Documents of the United States, were added to the Library, which on July 31 , 1944, was receiving currently 2,457 annuals and 1,340 periodicals. It is a subscribing member of twenty-six learned societies. All British Parliamentary Papers are received regularly by the Library, which is also a "library of deposit" for the Public Documents of the United States. The total number of bound volumes now in the Library is 258,360 .

\section{CHEMICAL EDUCATION}

$\mathrm{A}^{\mathrm{T}}$ $\mathrm{T}$ a joint meeting of the London Sections of the Royal Institute of Chemistry and the British Association of Chemists, and of the London Area Section of the Association of Scientific Workers, held in London on February 21, a spirited discussion on "Chemical Education" took place. The chair was taken by Dr. G. L. Riddell, chairman of the London and South-Fastern Counties Section of the Royal Institute of Chemistry.

Various aspects of the subject were introduced by different speakers. Dr. J. R. Nicholls gave his views on the knowledge and skill expected from an analytical chemist. He stressed the need for training in fundamental chemistry and in the principles underlying the various analytical procedures. Speed and accuracy are essential and keen powers of observation are required. He suggested that chemical education should include some account of the factors which determine whether a particular chemical reaction is suitable for use on a large scale, and concluded by regretting that there are no chairs of analytical chemistry at British universities and no academic schools of research in analysis.

Dr. F. W. Stoyle discussed the requirements of a work's chemist. He said that too high a degree of specialization in a degree course should be discouraged. At the same time, efforts should be made to give students an idea of the similarities and differences between laboratory and works practice by occasional visits to factories. After employment, the graduate chemist should supplement his academic training by courses in technology and ancillary subjects such as costing, factory legislation, etc. He should attempt to improve factory technique while making due allow. ance for the craft of the operative.
Mr. F. A. Robinson spoke on "What is Expected of the Research Chemist". $\mathrm{He}$ is of the opinion that the primary requirement is a sound grasp of the principles of scientific research and, secondly, an ability to apply these to whatever problems are encountered. He must also be gifted with a healthy scepticism, inventiveness, patience, the ability to read intelligently and an interest in the utilitarian aspect of his work. The latter quality is, perhaps, most neglected in a university training, and might be fostered by informing the student of technological as well as academic discoveries.

Dr. J. Kenyon, speaking on university training, pointed out that chemistry is a wonderful blend of craft and science, and that the training of the chemist is, therefore, twofold in character. In the laboratory the aim is to acquire manipulative skill and develop powers of observation and deduction, while in the lecture room the fundamental principles of the science are acquired. He stressed the importance of the latter, stating that he does not conceive it to be the function of university training to produce youthful specialists ready to fulfil the specific requirements of any particular industry. Its function is rather to supply young men and women capable of applying the results of their training - a skilled hand, an observing eye, a well-stored mind, a critical judgment and a logical intellect-to meet the varied demands of chemical industry.

Dr. A. J. Jinkings spoke on the technical training of the chemist. He affirmed that full-time day courses at a university or technical college are somewhat academic in character and that emphasis is rightly placed on principles rather than on applications. Greater co-operation is needed between the universities and technical colleges, and more technical college courses should be regarded as adequate qualifications for a degree. He suggested that a faculty of technology in the University of London and a national technological institute to grant degrees and to co-ordinate and supervise technical training generally would be of outstanding value.

Dr. E. A. Rudge paid high tribute to the sterling qualities of the part-time graduate, who, he said, stands high in industrial value. Against the advantages he shows in training and experience, however, are serious disadvantages of narrowness in outlook, since he lacks the experience of academic life. He suggested that this could be overcome by wider provision for part-time day classes which should be integrated, where possible, into the academic course.

The discussion which followed was summarized by Dr. C. G. Anderson. A number of contributors said that during university chemical courses a certain amount of technological training and some knowledge of standard forms of plant should be given, so that graduates should not be completely at a loss on entering industry. This training would be helped by interchange between industrial chemists and university teachers, by works visits and vacation employment in industry. Training should also be given in the use of literature. Students should be given some idea of the conditions, requirements and possibilities in industry in order that they may select, to some extent, the type of work for which they are fitted. More attention should be paid to inculcating the scientific outlook quite early in ordinary school training. Part-time evening study, while valuable, is too strenuous, and more day training and State bursaries for full-time study are desirable. The opinion was expressed that there should be refresher courses 